\title{
Protected Areas for Conflict Resolution and Management of Recreational and Commercial Fisheries
}

\author{
Quach Thi Khanh Ngoc \\ Norwegian College of Fishery Science, University of Tromso \\ Faculty of Economics, Nha Trang University, Vietnam
}

Ola Flaaten

Norwegian College of Fishery Science, University of Tromso

\begin{abstract}
This paper investigates interactions between recreational and commercial fisheries. It introduces the idea of a protected area for recreational fisheries, as a way to reduce conflict between the two sectors and to preserve the natural resource. It is demonstrated that without a protected area for recreational fisheries, open access may imply that only one sector survives. A protected area can assure the operation of both sectors, even under open access. This measure also enhances the aggregate fish stock and the aggregate harvest, both in open access and in the optimal management of recreational fisheries, even if commercial fisheries operate under an open access regime.
\end{abstract}

Key words: protected area for recreational fisheries, bioeconomic modeling, recreational fisheries, recreational and commercial fisheries interactions. 


\section{Introduction}

Like commercial fisheries, the number of participants in recreational fisheries is significantly increasing around the world due to increases in wealth, leisure time, and tourism. In developed countries, $2.4 \%$ of the population participates in recreational fishing (e.g. Germany: 2.1\%; USA: 2.8\%; UK: 3.5\% (freshwater only); Europe: 4.7\%) (Pitcher and Hollingworth, 2002). In Nordic countries, the statistics for participation are: Denmark: 12.5\%; Iceland: 31.5\%; Sweden: 35\%; Finland: 40\%; Norway: 50\% (Toivonen, 2002). In developing countries (e.g. South African line fisheries), only half of one percent of the population appears to be involved in fishing as a sport (Griffiths and Lamberth, 2002). The increasing number of participants in recreational fishing has placed pressure on marine resources. In Canada, there was evidence of dramatic declines in four high-profile fisheries, including 2 salmonid species, 1 percid species and 1 esocid species attributable to recreational fisheries (Post et al., 2002). In the United States, fish populations have declined in several coastal regions and recreational fisheries (in addition to commercial fisheries) were contributing to those declines (Coleman et al., 2004).

Desire to preserve resources requires more understanding of management measures in recreational fisheries and the conflicts with commercial fisheries as well. In Australia, McPhee et al. (2002) suggest that, due to conflicts with commercial fisheries and without changes to the management and monitoring of recreational fisheries, resources may not be sustainable in the long term. Pitcher and Hollingworth 
(2002) state that conflicts between recreational fisheries and commercial fisheries are notorious thus management decision should be taken with the presence of the information related to the aforementioned conflicts. Such conflicts are not always simple to define and they are a topic that has been studied by ecological fisheries and economic scientists (Pitcher and Hollingworth, 2002).

Economic literature often deals with inefficient allocation of the resources under open access and it often examines efficient allocation that maximizes the present discounted value of recreational and commercial benefits (Connell and Sutinen, 1979). This research applied the bioeconomic model in the recreational context where angler demand is solely a function of the quantity of trips and the harvest per trip. It examined the allocation issue of a fishery, exploited by both recreational and commercial fishermen under open access and optimal management. Bishop and Samples (1980) consider the issue of the optimal harvest allocation of a fishery that is shared between commercial and recreational fisheries, by adding a recreational sector to a standard commercial fishing optimal control model. Laukkanen (2001) studied the optimal exploitation strategy for four sequential fisheries, of which one was a recreational fishery. Sumaila (2002) studied how the coexistence of sport and commercial fisheries in Namibian can be managed using the Nash equilibrium game theory.

In this paper, we develop a bioeconomic model to address the competition and management of recreational and commercial fisheries. We study harvest strategies, 
focusing on the allocation of catches between these fisheries. The benefits of both fisheries are measured in terms of catch rather than effort. We depart from Bishop's model because we study recreational and commercial fisheries in a standard bioeconomic model. However, we investigate the open access management regime for both sectors as a base for further discussion. A consequence of open access in the two sectors is that one of the sectors may have to close down. We introduce a protected area for the recreational fishery as a measure to solve the conflict. The establishment of a protected area for the recreational fishery aims to protect and maintain the fishing ground for the recreational fishery and to reduce conflicts with the commercial fishery. Within a bioeconomic framework, we compare the aggregate stock and aggregate harvest before and after the establishment of a protected area for the recreational fishery. This is done to see if it helps to achieve equity in spatial resource allocation for participants. The comparison is also useful in examining how a protected area can contribute to a fishery management objective. We also suggest using the protected area as a management tool for recreational fisheries since, as for marine reserves, this may be easier to enforce and the data requirement for effective management may be low compared to other management schemes (Pezzey et al., 2000). To the best of our knowledge, the protected area modeling of recreational-commercial fisheries is novel.

Whether or not a protected area for recreational fisheries is established, the commercial fishery, by assumption, operates under open access conditions. Several investigations regarding the open access commercial fishery with the presence of a notake marine reserve have been conducted (see e.g. Flaaten and Mjolhus (2006); 
Pezzey et al. (2000); Sanchirico and Wilen (2001)). These papers have analyzed and focused directly on the cost and benefits of a marine reserve for fisheries management. The open access regime is chosen to examine whether a marine reserve can create social and ecological benefits and work as a management tool, instead of applying conventional tools, such as fish quotas, effort licenses, seasonal closures, and gear restrictions.

The paper is organized as follows. In Section 2, the basic bioeconomic model is presented and we explore recreational-commercial fisheries' conflicts and management, when the recreational fishery is without a protected area. In Section 3, we analyze the interaction between recreational and commercial fisheries when the protected area is established for the recreational fishery. In Section 4, we compare different management regimes, the aggregate stock, and aggregate harvest, before and after the creation of a protected area for the recreational fishery. Finally, in Section 5, we conclude the paper with a discussion of its findings.

\section{The basic model}

In this section, we consider the characteristics of a basic fishery model without the protected area. We assume that a fish stock is located in an area unit size and that the natural growth rate for fish population exhibits logistic growth pattern, thus

$$
G(S)=r S(1-S),
$$


where $S$ is the size of fish population, $r$ is the intrinsic growth rate. It should be noted that carrying capacity is normalized to one and $G(S)$ is a strictly concave function. The rate of change of the stock with the presence of the harvests is given by

$$
\frac{d S}{d t}=r S(1-S)-g-h
$$

$g$ and $h$ are the harvests from recreational and commercial fisheries respectively.

Above, equation (2) is the ecological model, which shows the relationship between the harvest and the change in stock biomass. However, the harvest activity is also determined by economic considerations. In order to develop the main analysis, we will provide a simple model, which allows for the economic analysis of a fishery, jointly exploited by recreational anglers and commercial fishermen. Since the utility of recreational anglers does not relate directly to fish consumed (as it does with commercial fisherman) we will use in this study the benefit function for both recreational and commercial fisheries.

Following Bishop and Samples (1980), we assume that $v(S)$ is the gross benefit per unit of fish caught by recreational anglers, $v^{\prime}(S)>0$, and $j(S)$ is the average cost of catching fish in the recreational fishery, $j^{\prime}(S)<0$. Thus $R(S)=v(S)-j(S)$ is the net benefit per unit of fish caught recreationally, where $R^{\prime}(S)>0$. The demand for recreational catch is perfectly elastic with respect to $g$. Bishop and Samples (1980) 
measured the success of anglers by the fish catch per day and they assumed that the catch per day is positively related to the stock size; so the gross benefit per unit of fish caught is a function of stock. Below we assume that $v(S)$ is proportional to S.

For the commercial fishery, let $p$ be the price per unit of commercial catch, where demand is assumed to be perfectly elastic and $c(S)$ be the cost of catching per unit of fish caught $c^{\prime}(S)<0$. Hence $C(S)=p-c(S)$ is the rent, or benefit per unit, of fish caught commercially. Note that demands for recreational and commercial catches are perfectly elastic and effort costs are linear in effort; thus, there is no consumer surplus or producer surplus generated in our analysis.

\subsection{Open access equilibrium}

Open access, bioeconomic equilibrium occurs when there is no incentive for individuals to enter or to leave the fishery. In this case, there is simultaneously economic and biological equilibrium, with the aggregate harvest equaling the fish growth. The open access bioeconomic equilibrium of a joint recreational and commercial fishery only occurs in this model when the benefit from recreational fishery is zero and, simultaneously, the rent from commercial fishery is zero. The open access equilibrium point is implicitly defined by

$$
\begin{aligned}
& R(S) g=0, \\
& C(S) h=0,
\end{aligned}
$$




$$
\frac{d S}{d t}=r S(1-S)-g-h=0 .
$$

(3) and (4) imply that each sector will approaches the open access equilibrium when they harvest the stock to their zero net benefit level. Thus, a general equilibrium requires that the net benefit functions of both sectors simultaneously equal zero. For the purpose of further analysis, we assume the net benefit functions for recreational and commercial fisheries as

$$
\begin{aligned}
& R(S)=a S-\frac{c_{R}}{S}, \\
& C(S)=p-\frac{c_{C}}{S},
\end{aligned}
$$

where $a, c_{R}, p$ and $c_{C}$ are parameters.

The open access condition for the fisheries can be obtained by setting (6) and (7) equal to zero. However, the difference in cost efficiency may lead to interactions between the two sectors. The activity of the commercial fishery may affect the recreational fishery and vice versa. In order to examine this interaction, it is useful to investigate first the open access equilibrium stock levels for fish, solely exploited by a recreational or a commercial fishery. These stock levels are as follows

$$
\begin{aligned}
& S_{R}^{\infty}=\sqrt{\frac{c_{R}}{a}}, \\
& S_{C}^{\infty}=\frac{c_{C}}{p} .
\end{aligned}
$$


(8) and (9) are open access stock levels of recreational fisheries and commercial respectively. If the fish stock exceeds $\sqrt{\frac{c_{R}}{a}}$ or $\frac{c_{C}}{p}$, additional anglers or fishermen would be attracted to the fishery. The effort will increase and make the stock decrease to the open access level of each fishery. Anglers or fishermen may continue to fish until the net benefit is down to zero or until the stock level approaches equation (8) for recreational fisheries or equation (9) for commercial fisheries.

By contrast, when the population is exploited by both recreational and commercial fisheries, there will be conflicts between them. Both recreational anglers and commercial fishermen will compete for the fishing areas and fishing harvests. One significant question arisen here is: what is the equilibrium point in this joint fishery? There are three possibilities; the two fisheries are equally cost efficient, the commercial fishery is most cost efficient, or the recreational fishery is most cost efficient. The present analysis will go through each possibility and examine how the conflicts between two sectors may affect the equilibrium stock and harvest of the fisheries.

i) If we assume that

$$
S^{\infty}=\frac{c_{C}}{p}=\sqrt{\frac{c_{R}}{a}},
$$

it is immediately clear that the general open access stock equilibrium of a joint commercial and recreational fishery can be achieved. At this stock level, both sectors 
coexist in the fishery. The aggregate equilibrium harvest for the two fisheries can be stated as

$$
g^{\infty}+h^{\infty}=r \sqrt{\frac{c_{R}}{a}}\left(1-\sqrt{\frac{c_{R}}{a}}\right)=r \frac{c_{C}}{p}\left(1-\frac{c_{C}}{p}\right) .
$$

Equation (10) is a strict constraint for a general equilibrium. A change of one of the parameters can violate this constraint and it is possible that either the recreational anglers or the commercial fishermen have to leave the fishery.

ii) Assume that $S^{\infty}=\sqrt{\frac{c_{R}}{a}}<\frac{c_{C}}{p}$. In this case, the recreational fishery is more advanced than the commercial fishery, in the sense that its combined technology, costs, and market values put more pressure on the stock than that of the commercial fishery. The commercial fishermen will have to leave the fishery. The fishery is only exploited by recreational anglers so the equilibrium harvest for the fishery becomes

$$
g^{\infty}=r S(1-S)=r \sqrt{\frac{c_{R}}{a}}\left(1-\sqrt{\frac{c_{R}}{a}}\right) .
$$

iii) Now suppose that $S^{\infty}=\frac{c_{C}}{p}<\sqrt{\frac{c_{R}}{a}}$. The net benefit from the harvest of recreational fisheries is negative. Thus, in contrast with ii), the recreational anglers will leave the fishery. The fishery is solely exploited by commercial fishermen so the equilibrium harvest for the fishery in this case can be defined by

$$
h^{\infty}=r S(1-S)=r \frac{c_{C}}{p}\left(1-\frac{c_{C}}{p}\right) .
$$


Both recreational and commercial harvests cannot exceed the catchable stock (the natural growth rate of the fish stock). Although the equilibrium harvest in both cases (i) and (ii) equals the natural growth rate of the fish stock, the harvest of commercial fishermen in case (ii) is different from that of recreational anglers in case (i). The reason for this is due to the difference in cost efficiency. The difference in the cost affects the level of equilibrium fish stock and in turn, affects the harvest rate. Our fish stock in coastal oceans is more likely to be overexploited than underexploited. Consequently, a higher cost may lead to an increase in the fish stock and this in turn, makes the equilibrium harvest also increase. The magnitude of the harvest of two sectors therefore depends mostly on the magnitude of the cost exerting from their activities.

i) and ii) are cases where a general equilibrium point for both sectors cannot be achieved. The open access combination of recreational and commercial fishing does not assure the operation of both sectors. The question of how to manage each sector, provided the other sector operates under open access, will be studied. As the commercial fishery, by assumption, always operates under open access conditions, we will discuss appropriate management measures for a recreational fishery to achieve an equilibrium with the harvest in both sectors.

\subsection{Management strategies for a recreational fishery with competition from an open access commercial fishery}


As discussed above, open access for both fisheries' sectors gives rise to three cases; coexistence of the two fisheries, commercial fisheries only, or recreational fisheries only. In the first case, due to equilibrium open access stock levels of two sectors are equal to each other, the operation strategy would be to allow open-access regimes in both fisheries. Here, we will only examine the last two cases in order to investigate the appropriate management strategy for the recreational fishery, assuming that the commercial fishery remains as an open-access fishery.

i) The recreational fishery is more efficient than commercial fishery, $S_{R}^{\infty}<S_{C}^{\infty}$

Maybe we should not expect to find it in actual fisheries. Since, if the recreational fishery were more efficient than the commercial fishery, then rational commercial fishermen would change and use the same fishing technology as the recreational anglers. Nevertheless, let us assume that the manager's problem is whether to choose a management plan for the recreational fishery, with the constraint that there exists an actual or possible open-access commercial fishery with the equilibrium stock level $S_{C}^{\infty}=\frac{c_{C}}{p}$.

We assume that the manager uses the optimal strategy, which follows from maximizing the present value of the recreational fishery benefit. We know from Clark and Munro (1975) that, in the case of an autonomous model with harvest that is linear in effort, there exists a long run optimal steady state and the optimal path towards 
steady state is the most rapid approach. Thus, we proceed by focusing on the optimal steady state. The objective function is then given by

$$
\max P V(g)=\int_{0}^{\infty} e^{-\delta t} R(S) g d t
$$

subject to

$$
\begin{aligned}
& \frac{d S}{d t}=G(S)-g-h^{\infty}, \\
& 0 \leq g \leq g_{\max }, \\
& S(0)=S_{0},
\end{aligned}
$$

where $\delta$ is social discount rate and $g_{\max }$ is a constraint on the harvest capacity of the recreational sector. Constraint (17) is an initial condition, that at $t=0, S$ stands at some value of $S_{0}$.

The objective of this problem is to choose an optimal control $g(t)$ for all t such that $P V$ is maximized without exceeding the natural growth rate of the fish stock. The Hamiltonian resulting from this maximization problem can be expressed as follows

$$
\begin{aligned}
H & \left.=e^{-\delta t} R(S) g+\lambda \mid G(S)-g-h^{\infty}\right], \\
& =\left(e^{-\delta t} R(S)-\lambda\right) g+\lambda\left(G(S)-h^{\infty}\right),
\end{aligned}
$$

where $\lambda$ is the current value shadow price. It is also known as the adjoint variable. The adjoint equation is defined by

$$
-\dot{\lambda}=\frac{\partial H}{\partial S}=e^{-\delta t} R^{\prime}(S) g+\lambda G^{\prime}(S) .
$$


Since the Hamiltonian is linear in control variable $g$, the switching function will determine the optimal level of catch for the recreational anglers in the fishery. The switching function is defined by $\sigma(t)=e^{-\delta t} R(S)-\lambda$. Thus, if $\sigma(t)>0, g=g_{\max }$ and if $\sigma(t)<0, g=0$. In the case $\sigma(t)=0$, the recreational harvest is on the singular path. Clark and Munro (1975) show that the vanish of switching function implies an singular solution for $S$ that can be stated by the following equation

$$
G^{\prime}\left(S_{R}^{*}\right)+\frac{R^{\prime}\left(S_{R}^{*}\right)\left(G\left(S_{R}^{*}\right)-h^{\infty}\right)}{R\left(S_{R}^{*}\right)}=\delta .
$$

$S_{R}^{*}$ is the optimal level of the fish stock if the recreational fishery is optimal along the time path.

Equation (20) is obtained from evaluating the singular time path $\sigma(t)=e^{-\delta t} R(S)-\lambda=0$ and the adjoint equation. This equation is also known as golden rules in the fishery. It states that the optimal stock level for the recreational fishery is the level that maximizes the benefit. The presence of an open access commercial fishery impacts on the fish stock and, naturally, it impacts on the management strategy for the recreational fishery. The optimal harvest policy for recreational fisheries will depend on the open access stock level for commercial fisheries. Thus, the optimal approach for the recreational fishery to the general equilibrium can be stated as

$$
g^{*}(t)=\left\{\begin{array}{lll}
g_{\max } & & c_{c} / p>S_{R}^{*} \\
G\left(S_{R}^{*}\right)-h^{\infty} & \text { whenever } & c_{C} / p=S_{R}^{*} \\
0 & & c_{C} / p<S_{R}^{*}
\end{array}\right.
$$


With $\frac{c_{C}}{p}>S_{R}^{*}$, the harvest rate $g_{\max }$ will drive the stock $S=\frac{c_{C}}{p}$ toward $S_{R}^{*}$ and the commercial fishermen would have to exit the fishery. This result contradicts the assumption that the commercial fishery may operate under open access conditions. On the other hand, the case $\frac{c_{C}}{p}<S_{R}^{*}$ implies that there is no participation of recreational anglers in the fishery. Only at the steady state equilibrium of $S_{R}^{*}=\frac{c_{C}}{p}$ may the two sectors coexist in the fishery. The commercial fishery operates under its open access condition while the recreational fishery operates under some form of management restriction that allows $g^{*}=G\left(S_{R}^{*}\right)-h^{\infty}$. Note that this implies a need for a mechanism to share the total catch between the two fisheries.

The steady state optimal solution may be achieved by use of harvest or effort control, as well as fees (Clark, 2005). For the recreational fishery, Connell and Sutinen (1979) suggest that in order to obtain the optimal harvest in the steady state, the manager can impose a user fee per unit of harvest. In this paper, the user fee is determined by setting switching function equal to zero and it is equal to $e^{\delta t} \lambda$. Following Clark (2005), p. 315, $e^{\delta t} \lambda$ can be solved from adjoint equation (20) as

$$
e^{\delta t} \lambda=\frac{R^{\prime}\left(S_{R}^{*}\right) g}{\delta-G^{\prime}\left(S_{R}^{*}\right)}=\frac{R^{\prime}\left(S_{R}^{*}\right)\left[G\left(S_{R}^{*}\right)-h^{\infty}\right]}{\delta-G^{\prime}\left(S_{R}^{*}\right)} .
$$

The application of the user fee implies that the recreational anglers will adjust their activity until the net benefit equal to $e^{\delta t} \lambda$. At this point, the harvest of 
recreational anglers would be optimal. The user fee is determined by the steady state stock and the open access catch level from commercial fisheries, and at this level, it stays constant. If the cost-price ratio $\frac{c_{C}}{p}$ of the commercial fishery increases, the commercial harvest may decrease or increase. This depends on whether the stock is biologically underexploited or overexploited. If the stock is biological overexploited, an increase in cost-price ratio, $\frac{c_{C}}{p}$ leads to an increase in commercial harvest. In this case, the steady stock increases and the user fee decreases. If the stock is biological underexploited, an increase in cost-price ratio $\frac{c_{C}}{p}$ leads to a decrease in commercial harvest. In this situation, the steady state stock increases and the user fee also increases.

(ii) The recreational fishery is less efficient than the commercial fishery, $S_{C}^{\infty}<S_{R}^{\infty}$

In this case, the recreational anglers will not participate in the fishery since the stock level at open access is too low. Under this scheme, the spatial zoning approach is an appropriate management tool that can secure the operation of recreational fisheries since it provides the security for recreational fisheries through exclusion of commercial fisheries. Also, in relation to case (i) $S_{C}^{\infty}>S_{R}^{\infty}$, spatial zoning can be used for a similar purpose - to allow the two fisheries to coexist.

\section{Protected areas for recreational fisheries}


The theory of spatial zoning focuses on the selection of a protected area and its size. There are two core objectives that motivate the creation of protected areas: conservation and sustainable provisions for human use (Kar and Matsuda, 2008). The second goal, relating to human use, includes the management of fisheries, recreation, education, and research. Therefore, there are many different types of protected areas, with different levels of protection, ranging from areas that allow certain extraction activity to those that are strictly no-take reserves. Bohnsack (1993) argues that a protected area reduces conflicts between user groups by physically separating the interests of fisheries and non-fisheries. In this paper, we introduce a protected area for the recreational fishery as a measure to reduce conflicts between recreational and commercial fisheries by separating the fishing grounds into two. There are some examples of zoning mechanisms like this in Australia. Here, the Great Barrier Reef Marine Park has some zones that allow recreational use only. In New South Wales, 30 Recreational Fishing Havens have been established utilizing fisheries management closures that exclude commercial fishing (Rayns et al., 2006). In this section, we will discuss how a protected area for recreational fisheries may assist in resource allocation for recreational anglers, and how the aggregate stock and harvests are affected by a protected area.

Most bioeconomic models of protected areas are developed to examine the effects of protected areas (normally no-take reserves) on commercial fisheries. Our model is designed to analyze the impact on recreational and commercial fishing of a protected area for recreational fisheries. The common approach in the bioeconomic 
models is to divide the marine environment into two patches, one for protection, and one for fishing. In our case, a protected area for recreational fisheries segregates the fishing activities of two sectors in two different fishing grounds. The commercial fishermen only fish outside the protected area. We will consider the relationship between these different groups; recreational anglers and the commercial fishermen.

The creation of a protected area for a recreational fishery leads to a fraction $m$ of the total area of unit size that must be set aside for the recreational fishery; and $1-m$ is the area for the commercial fishery. Since the recreational sector operates inside the protected area and the commercial sector operates in the outer area, we define $S_{R_{m}}$ and $S_{C_{m}}$ as population stocks and $G\left(S_{R_{m}}\right)$ and $G\left(S_{C_{m}}\right)$ as the natural growth rates of the population inside and outside the protected area. The natural growth rates are assumed as follows

$$
\begin{aligned}
& G\left(S_{R_{m}}\right)=r S_{R_{m}}\left(1-\frac{S_{R_{m}}}{m}\right), \\
& G\left(S_{C_{m}}\right)=r S_{C_{m}}\left(1-\frac{S_{C_{m}}}{1-m}\right) .
\end{aligned}
$$

Assuming that the migration between the protected area and the outside area occurs, the rates of change in biomass, inside and outside the protected area, are modeled as follows

$$
\begin{aligned}
& \frac{d S_{R_{m}}}{d t}=G\left(S_{R_{m}}\right)-z\left(\frac{S_{R_{m}}}{m}-\frac{S_{C_{m}}}{1-m}\right)-g_{m}, \\
& \frac{d S_{C_{m}}}{d t}=G\left(S_{C_{m}}\right)+z\left(\frac{S_{R_{m}}}{m}-\frac{S_{C_{m}}}{1-m}\right)-h_{m},
\end{aligned}
$$


where $z$ is the migration rate, $g_{m}$ is the recreational harvest and $h_{m}$ is the commercial harvest after the protected area is established. These two dynamic equations will be used to analyze firstly, the open-access equilibrium, then the optimal management of the recreational fishery within this reserve framework.

\subsection{Open access equilibrium}

Although the participants of the two sectors are exploited in the different patches and in the different fish stocks, the question of how to allocate the total harvest and the resource between recreational fisheries and commercial fisheries is of interest. There are some key reasons for this. First, there is a biological linkage between the two patches due to the dispersal of fish between them; so the rate of change of the fish stock will involve the growth of the fish stock and the dispersal process. Second, the way to allocate the resource will have consequences on the sustainability of the stock, the amount of market value from the resource, and the social and environmental objectives of the fisheries (Sumaila, 2002).

The benefits for recreational anglers and commercial fishermen are defined as

$R\left(S_{R_{m}}\right) g_{m}$ and $C\left(S_{C_{m}}\right) h_{m}$, respectively. The open access dissipates the benefits (rents) of the two sectors. To examine the open access regime for both sectors and to investigate the problem of the fishery in relation to the creation of the protected area for recreational fisheries, the benefit functions are modified as 


$$
\begin{aligned}
& R\left(\frac{S_{R_{m}}}{m}\right)=a \frac{S_{R_{m}}}{m}-\frac{c_{R}}{S_{R_{m}}} m, \\
& C\left(\frac{S_{C_{m}}}{1-m}\right)=p-\frac{c_{C}}{S_{C_{m}}}(1-m) .
\end{aligned}
$$

The open access equilibrium stocks in the two patches can be defined by setting the net benefits in (27) and (28) equal to zero

$$
\begin{aligned}
& S_{R_{m}}^{\infty}=m \sqrt{\frac{c_{R}}{a}}, \\
& S_{C_{m}}^{\infty}=(1-m) \frac{c_{C}}{p} .
\end{aligned}
$$

Equation (29) and equation (30) show that an expansion of the protected area directly affects the open access equilibrium sub-stock. It increases the open access stock inside the protected area but it decreases the equilibrium stock in the outer area. Only when $m=\frac{\frac{c_{C}}{p}}{\sqrt{\frac{c_{R}}{a}}+\frac{c_{C}}{p}}$, the open access equilibrium stock in both patches will equal each other. So if $m<\frac{\frac{c_{C}}{p}}{\sqrt{\frac{c_{R}}{a}}+\frac{c_{C}}{p}}$, then $S_{R_{m}}^{\infty}<S_{C_{m}}^{\infty}$ and if $m>\frac{\frac{c_{C}}{p}}{\sqrt{\frac{c_{R}}{a}}+\frac{c_{C}}{p}}$, then $S_{R_{m}}^{\infty}>S_{C_{m}}^{\infty}$. $m$ can be seen as a resource allocation parameter. The choice of $m$ may impact on the stock level for recreational and commercial fishing and consequently, it will affect recreational and commercial harvests. 
If we substitute the open access stocks from (29) and (30) into (25) and (26) and let them equal zero, the equilibrium harvests for recreational and commercial fisheries, which include two components, the natural growth rate, and the migration rate between two patches can be found as

$$
\begin{aligned}
& g_{m}^{\infty}=r \sqrt{\frac{c_{R}}{a}} m\left(1-\sqrt{\frac{c_{R}}{a}}\right)-z\left(\sqrt{\frac{c_{R}}{a}}-\frac{c_{C}}{p}\right), \\
& h_{m}^{\infty}=r \frac{c_{C}}{p}(1-m)\left(1-\frac{c_{C}}{p}\right)+z\left(\sqrt{\frac{c_{R}}{a}}-\frac{c_{C}}{p}\right) .
\end{aligned}
$$

where $g_{m}^{\infty}$ and $h_{m}^{\infty}$ are the equilibrium harvests for recreational and commercial fisheries with the creation of the protected area under open access condition, respectively. The aggregate harvest can be obtained by adding (31) and (32) and it equals combining natural growth rate of the fish stock inside and outside the protected area. The aggregate harvest therefore gives the relationship between the fish abundance inside and outside the protected area and the harvests there.

There is an interaction between two sectors, which may affect the harvest of each sector. Fishing activity, inside and outside the protected area, reduces stock density. The relative density of the population will determine the dispersal between the two patches. Thus, even fishing in different fishing grounds, the activity of commercial fishermen may affect that of recreational anglers and vice versa. If the biological parameters $r$ and $z$ are assumed as given, then both the recreational and commercial harvest become a function of economic parameters $\frac{c_{C}}{p}$ and $\sqrt{\frac{c_{R}}{a}}$. An increase in the cost of commercial fishing will make the stock outside the protected 
area increase. This may help the recreational harvest increase due to the benefit from the dispersal from the outer area into the protected area.

From (31) and (32), it can be seen that both sectors may coexist when the protected area is created even if they operate under open access condition and if they are different in cost efficiency. However, it should be noted that the open-access steady state harvest from one of two fisheries may still be zero. When the growth rate in the protected area is equal to, or less than, the emigration from the protected area to the outer area, the recreational fishing must cease. When the growth rate of the outer area is equal to, or less than, emigration from the outer area to the protected area, commercial fishing must cease. This makes sense, as the migration exceeding the natural growth seems unable to sustain the ecological equilibrium with positive stock within each patch.

The commercial and recreational fisheries, under open access, imply that the establishment of protected areas, with an open access regime for commercial fishing outside and especially recreational fishing inside, still result in inefficiencies. The fishermen and the anglers continue to increase their efforts until their benefit equals zero. Further, because of the dispersal between the two patches, the aggregate stock will be fished down. It is assumed that $S_{R_{m}}^{\infty}$ is open access stock inside the protected area that makes the net benefit of anglers equal to zero. A level of $S_{R_{m}}>S_{R_{m}}^{\infty}$ will make the net benefit for recreational fisheries positive, so it will attract more anglers entering the fisheries and make the stock decrease. At the high level of $S_{R_{m}}$, the 
dispersal of fish from the protected area to the fishing ground also increases. This can lead to the equilibrium catch of commercial fishermen, $h_{m}^{\infty}$ increasing and therefore, more fishermen will enter the fisheries and ultimately, may fish down the stock.

\subsection{Optimal management of the recreational fisheries and open access for the} commercial fisheries

Now we assume that the recreational fishery is managed to maximize the resource rent of this fishery. The equilibrium stock outside the protected area reads as $S_{C_{m}}^{\infty}=\frac{c_{C}}{p}(1-m)$. To formalize the objective function of the manager we write formally

$$
\max P V\left(g_{m}\right)=\int_{0}^{\infty} e^{-\delta t} R\left(S_{R_{m}}\right) g_{m} d t
$$

subject to

$$
\begin{aligned}
& \frac{d S_{R_{m}}}{d t}=G\left(S_{R_{m}}\right)-z\left(\frac{S_{R_{m}}}{m}-\frac{c}{p}\right)-g_{m}, \\
& 0 \leq g \leq g_{m}^{\max }, \\
& S_{R_{m}}(0)=S_{0} .
\end{aligned}
$$

The current-value Hamiltonian is

$$
\begin{gathered}
H=e^{-\delta t} R\left(S_{R_{m}}\right) g_{m}+\lambda\left[G\left(S_{R_{m}}\right)-z\left(\frac{S_{R_{m}}}{m}-\frac{c_{C}}{p}\right)-g_{m}\right], \\
=\left(e^{-\delta t} R\left(S_{R_{m}}\right)-\lambda\right) g_{m}+\lambda\left[G\left(S_{R_{m}}\right)-z\left(\frac{S_{R_{m}}}{m}-\frac{c_{C}}{p}\right)\right]
\end{gathered}
$$


with $g_{m}$ as the control variable, where $0 \leq g \leq g_{m}^{\max } ; S_{R_{m}}$ is state variable; $\lambda$ is adjoint variable, or shadow value of the population stock $S_{R_{m}}$ inside the protected area; and $\delta$ is social discounted rate.

The adjoint equation in this case is

$$
-\dot{\lambda}=\frac{\partial H}{\partial S_{R_{m}}}=e^{-\delta t} R^{\prime}\left(S_{R_{m}}\right) g_{m}+\lambda\left[G^{\prime}\left(S_{R_{m}}\right)-\frac{z}{m}\right] .
$$

As previously, a singular solution only arises when the coefficient of $g_{m}$ (the switching function, $\left.\sigma_{m}(t)=e^{-\delta t} R\left(S_{R_{m}}\right)-\lambda\right)$ is zero. The optimal equilibrium stock if the recreational fishery is optimal along the time path is found from evaluating singular path and adjoint equation as follows

$$
\left[G^{\prime}\left(S_{R_{m}}\right)-\frac{z}{m}\right]+\frac{R^{\prime}\left(S_{R_{m}}^{*}\right)}{R\left(S_{R_{m}}^{*}\right)}\left[G\left(S_{R_{m}}^{*}\right)-z\left(\frac{S_{R_{m}}^{*}}{m}-\frac{c}{p}\right)\right]=\delta
$$

where $R^{\prime}\left(S_{R_{m}}\right)$ and $G^{\prime}\left(S_{R_{m}}\right)$ are representative of partial derivatives of the net benefit function and the growth function for the protected area, with respect to the stock population.

The golden rule (39) can be explained the following way. The first component on the left-hand side, $\left[G^{\prime}\left(S_{R_{m}}\right)-\frac{z}{m}\right]$, is the marginal product of the optimal stock size 
$S_{R_{m}}^{*}$. The second component, $\frac{R^{\prime}\left(S_{R_{m}}^{*}\right)}{R\left(S_{R_{m}}^{*}\right)}\left[G\left(S_{R_{m}}^{*}\right)-z\left(\frac{S_{R_{m}}^{*}}{m}-\frac{c}{p}\right)\right]$, is the marginal stock effect emanating from the recreational fisheries. Therefore, (39) states that the optimal stock for recreational fisheries, $S_{R_{m}}^{*}$, is one at which the sum of the marginal product of the stock and the marginal stock effect equals the social rate of discount. Clark and Munro (1975) called this sum the own rate of interest of the stock. In this case, both the marginal productivity of the stock and the growth term of the marginal stock effect are adjusted for migration. The golden rule (39) equalizes the own rate of interest of the stock and the social rate of discount.

Equation (47) may be rewritten as

$$
\left[G^{\prime}\left(S_{R_{m}}^{*}\right)-\frac{z}{m}\right] R\left(S_{R_{m}}^{*}\right)+R^{\prime}\left(R_{R_{m}}^{*}\right)\left[G\left(S_{R_{m}}\right)-z\left(\frac{S_{R_{m}}}{m}-\frac{c_{C}}{p}\right)\right]=\delta R\left(S_{R_{m}}^{*}\right) .
$$

The left-hand side of (40) is the present value of the marginal sustainable benefit afforded by the marginal increment to the stock. Also, it can be interpreted as the marginal user cost - the cost of capturing the marginal increment of fish. The right-hand side is the marginal benefit from recreational fishing. Hence, the optimal fish stock $S_{R_{m}}^{*}$ is defined by equalizing the present value of the marginal user cost and the marginal benefit of harvesting.

Without the presence of protected area, the optimal strategy for recreational fisheries as we study in case (i) of previous section shows that at the steady state, 
$G\left(S_{R}^{*}\right)$ is allocated to recreational fisheries as a rate of $g^{*}$ and to commercial fisheries at a rate of $h^{\infty}$ such that the net benefit of recreational fisheries equals $e^{-\delta t} \lambda$ and the net benefit of commercial fisheries equals zero. The conflict between two sectors still exists. One of two sectors may be excludes if the level of fish stock falls below the level that can help them operate under their own management regime.

The creation of protected area for recreational fisheries helps to segregate the areas for recreational and commercial fishing. Thus $G\left(S_{R_{m}}^{*}\right)$ is only allocated for recreational fisheries and the activity of the recreational fisheries is assured. It is the same for commercial fisheries. The commercial harvest is assured by the natural growth rate $G\left(S_{C_{m}}\right)$ outside the protected area. The interaction between two sectors is only due to the dispersal process which depends on the density of the fish stock between the two parches.

The net benefit of recreational fisheries so far, has been studied as a function of economic parameters and the stock level inside the protected area. Let us investigate, in this case, how the net benefit of recreational fisheries affected by the fish stock inside and outside the protected area and by other relevant factors. The benefit from the recreational fisheries solved from (40) is given by

$$
R\left(S_{R_{m}}^{*}\right)=R^{\prime}\left(S_{R_{m}}^{*}\right) \frac{G\left(S_{R_{m}}^{*}\right)-z\left(\frac{S_{R_{m}}^{*}}{m}-\frac{c_{C}}{p}\right)}{\delta-G^{\prime}\left(S_{R_{m}}^{*}\right)+\frac{z}{m}} .
$$


As opposed to the open access solution that drives the stock to the zero net benefit level. Optimal management solution requires a reduction of harvest from recreational fisheries to where the benefit function satisfies (41). The net benefit of recreational fisheries is a function of cost-price ratio, $\frac{c_{C}}{p}$ of commercial fisheries and other biological parameters in both areas. It increases with the cost-price ratio and the intrinsic growth rate and decreases with the migration rate. This illustrates that the benefit of recreational fisheries is dependent on the dispersal between two patches; so it will depend on relative densities and hence, cost-price ratio outside the protected area. In contrast with the case without the protected area, the benefits in this case thus, must be considered in a system of ecologically-connected patches. Removing one unit from the stock, inside or outside the protected area, will affect spillover to another patch.

From (39) we can also obtain the steady state harvest for recreational fisheries as a function of the net benefit, marginal growth rate of fish stock and discounted rate

$$
g_{m}^{*}=\left(\delta-G^{\prime}\left(S_{R_{m}}^{*}\right)+\frac{z}{m}\right) \frac{R\left(S_{R_{m}}^{*}\right)}{R^{\prime}\left(S_{R_{m}}^{*}\right.} .
$$

The net benefit of harvested fish is an increase function of $S_{R_{m}}^{*}$ thus, when $S_{R_{m}}^{*}$ increases, the net benefit from harvest also increases and it leads to an increase in the harvest. 


\subsection{User fee for the recreational fisheries and open access for the commercial} fisheries

Instead of quantitative implementation of the optimal management for the recreational fisheries, the manager may impose a fee $f=e^{\delta t} \lambda$, on each unit of recreationallycaught fish. This will result in a steady state optimal fishery. From the switching function, we know that $e^{\delta t} \lambda=R\left(S_{R_{m}}\right)$.

The user fee can help the manager obtain optimal fishery management since the benefit function of recreational fishing, with the effect of the user fee, now becomes

$$
R\left(S_{R_{m}}\right) g_{m}-e^{\delta i} \lambda g_{m}=\left(R\left(S_{R_{m}}\right)-e^{\delta i} \lambda\right) g_{m} .
$$

The recreational anglers stop entering the fishery when the net benefit vanishes, so it is easy to see that

$$
R\left(S_{R_{m}}\right)-e^{\delta t} \lambda=0 .
$$

(44) is the same as the switching function in the singular path. The application of this user fee may adjust the level of recreational harvest to the optimal level even if the recreational fishery operates under open access condition. To examine the effects of the biological and economic parameters on the change of user fee $e^{\delta} \lambda$, (following Clark (2005), p. 315) equation (38) can be solved for $e^{\delta i} \lambda$, as follows 


$$
e^{\delta t} \lambda=R^{\prime}\left(S_{R_{m}}^{*}\right) \frac{G\left(S_{R_{m}}^{*}\right)-z\left(\frac{S_{R_{m}}^{*}}{m}-\frac{c_{C}}{p}\right)}{\delta-G^{\prime}\left(S_{R_{m}}^{*}\right)+\frac{z}{m}} .
$$

Equation (45) corresponds with $R\left(S_{R_{m}}\right)$ in (41). The optimal fee to be imposed on recreational fishing depends on the cost-price ratio of commercial fishing, the reserve size, and the migration rate. A high cost-price ratio and a high reserve size make the user fee increase, while a high migration rate works in the opposite way. $\lambda$ is the user cost of fish stock; $\lambda$ is zero if the growth of fish stock $S_{R_{m}}$ equals the dispersal from the protected area to the outer area, or if the stock is so abundant that the change in fish stock does not affect the marginal net benefit per unit of catch, $\left(R^{\prime}\left(S_{R_{m}}^{*}\right)=0\right)$. This implies that the change in $S_{R_{m}}$ can impact on the user cost $\lambda$. $S_{R_{m}}$ increases, causing increases in natural growth of the fish stock and net benefit from fishing. Consequently, $\lambda$ increases and the user fee on recreational fishing also increases.

Protected areas may help to maintaining the fishing opportunities for both recreational anglers and commercial fishermen since they separate fishing areas and in turn, this may reduce the costly conflicts between the users. However, if the fishery is unregulated, this may lead to a divergence between private and social benefits and costs. Consequently, protected areas cannot contribute to maintaining healthy fish populations. This point raises a need to develop, implement and enforce management measures after zoning. While the commercial fishery is difficult to control especially 
with the case of multispecies and small-scale fishery in developing countries, combination of protected areas and the imposition of the user fee on recreational fisheries may be an appropriate measure to manage and maintain the fish stock.

\section{Comparisons before and after the creation of the protected area}

To better understand and explain the role of the protected area for recreational fisheries, we should examine the aggregate stock and aggregate harvest increase when the protected area for recreational fishing is created. We will therefore compare the result, as regards stock size and harvest, before and after the establishment of the protected area for recreational fisheries. This comparison will show how the protected area can affect the operation of the two sectors and of the equilibrium point.

Table 1 presents the comparisons of the aggregate stock and aggregate harvests before and after creation of a protected area under open access condition for both recreational and commercial fisheries. The establishment of a protected area sets up possibilities for increases in aggregate stock and aggregate harvests. Whether the stock densities inside and outside the protected area are equal or not, the aggregate stock biomass and aggregate harvests after the creation of the protected area, are at least equal to, or larger than, those prior to the creation of the protected area. 
Table 1 - Comparisons of aggregate equilibrium stock and harvests before and after the creation of a protected area under open access condition for both sectors

Scenarios

$$
S_{C}^{\infty}=S_{R}^{\infty}
$$

$$
S_{C_{m}}^{\infty}=S_{R_{m}}^{\infty}
$$

Aggregate stock $\quad \frac{c_{C}}{p}=\sqrt{\frac{c_{R}}{a}}$

$$
\frac{c_{C}}{p}=\sqrt{\frac{c_{R}}{a}}
$$

Aggregate harvests $\quad g^{\infty}+h^{\infty}=r \frac{c_{C}}{p}\left(1-\frac{c_{C}}{p}\right)=r \sqrt{\frac{c_{R}}{a}}\left(1-\sqrt{\frac{c_{R}}{a}}\right) \quad r \frac{c_{C}}{p}\left(1-\frac{c_{C}}{p}\right)=r \sqrt{\frac{c_{R}}{a}}\left(1-\sqrt{\frac{c_{R}}{a}}\right)$

Scenarios

$$
S_{C}^{\infty}<S_{R}^{\infty}
$$

$$
S_{C_{m}}^{\infty}<S_{R_{m}}^{\infty}
$$

Aggregate stock $\quad \frac{c_{C}}{p}$

$$
\frac{c_{C}}{p}(1-m)+\sqrt{\frac{c_{R}}{a}} m
$$

Aggregate harvests $\quad h^{\infty}=r \frac{c_{C}}{p}\left(1-\frac{c_{C}}{p}\right) \quad g^{\infty}+h^{\infty}=r \sqrt{\frac{c_{R}}{a}} m\left(1-\sqrt{\frac{c_{R}}{a}}\right)+r \frac{c_{C}}{p}(1-m)\left(1-\frac{c_{C}}{p}\right)$

Scenarios

$$
S_{C}^{\infty}>S_{R}^{\infty}
$$

$$
S_{C_{m}}^{\infty}>S_{R_{m}}^{\infty}
$$

Aggregate stock $\quad \sqrt{\frac{c_{R}}{a}} \quad \frac{c_{C}}{p}(1-m)+\sqrt{\frac{c_{R}}{a}} m$

Aggregate harvests

$$
g^{\infty}=r \sqrt{\frac{c_{R}}{a}}\left(1-\sqrt{\frac{c_{R}}{a}}\right)
$$

$$
g^{\infty}+h^{\infty}=r \sqrt{\frac{c_{R}}{a}} m\left(1-\sqrt{\frac{c_{R}}{a}}\right)+r \frac{c_{C}}{p}(1-m)\left(1-\frac{c_{C}}{p}\right)
$$


In order to be able to address effectiveness of different management regimes for recreational fisheries after the creation of protected area, we make comparisons of aggregate stock and aggregate harvests between open access and optimal management regime for recreational fisheries. Table 2 displays these comparisons.

We know from the theory that the optimal stock level $S_{R_{m}}^{*}$ will be on the range $S_{R_{m}}^{\infty}<S_{R_{m}}^{*}<S_{M E Y}$, when $0<\delta<+\infty$. Only if the future is completely discounted ( $\delta=+\infty$ ), the optimal strategy is to exploit the stock to the level of bionomic equilibrium of the unregulated, open access fishery.

The optimal management for recreational fisheries enhances the stock inside a protected area; consequently, an aggregate stock also increases compared to open access situation. The magnitude of the aggregate harvests will depend on the magnitude of the stock level inside the protected area for recreational fisheries. When the optimal management is actually applied, the population inside a protected area for recreational fisheries increases and it begins to create a positive benefit for commercial fisheries, by dispersal flow. The harvest for open access commercial fisheries may be higher than that under open access for recreational fisheries. However, the aggregate harvests may increase or decrease. There are three possible cases: 
Table 2 - Comparisons of aggregate equilibrium stock and harvests between open access and optimal management regime for the recreational fisheries with creation of protected area

\begin{tabular}{lll}
\hline Variables & Aggregate stock & Aggregate harvests
\end{tabular}

Open access

$$
\frac{c_{C}}{p}(1-m)+\sqrt{\frac{c_{R}}{a}} m \quad r \sqrt{\frac{c_{R}}{a}} m\left(1-\sqrt{\frac{c_{R}}{a}}\right)+r \frac{c_{C}}{p}(1-m)\left(1-\frac{c_{C}}{p}\right)
$$

Optimal management

$$
\frac{c_{C}}{p}(1-m)+S_{R_{m}}^{*} \quad r S_{R_{m}}^{*}\left(1-\frac{S_{R_{m}}^{*}}{m}\right)+r \frac{c_{C}}{p}(1-m)\left(1-\frac{c_{C}}{p}\right)
$$

${ }^{1} S_{R_{m}}^{*}$ is the optimal stock level for a recreational fishery defined by (39).

i) If $S_{R_{m}}^{\infty} \leq S_{R_{m}}^{*} \leq \frac{m}{2}$, the aggregate harvest will increase, compared to the open access regime for recreational fisheries.

ii) If $S_{R_{m}}^{*}>S_{R_{m}}^{\infty}>\frac{m}{2}$, the aggregate harvest will decrease compared to the open access regime for recreational fisheries.

iii) If $S_{R_{m}}^{\infty}<\frac{m}{2}<S_{R_{m}}^{*}$, the problem is more complex. The aggregate harvest will either increase or decrease compared to the open access condition for recreational fisheries, depending on the magnitude of $S_{R_{m}}^{\infty}$ and $S_{R_{m}}^{*}$. 


\section{Discussion and conclusions}

This paper discusses a bioeconomic model of recreational and commercial fisheries and asks a pertinent question: in an open access fishery, can an area reserved for the exclusive use of one of two sectors maintain the co-existence of both recreational and commercial fisheries? Since the recreational anglers and commercial fishermen compete for the same fish, the allocation of all or part of the resource to one group, impacts on the resources available to the other group. Under open access, each sector harvests the stock to the level where the net benefit of each fishery is dissipated, so the open access solution may occur with one or both of the sectors. The participants in one of the sectors may have to leave the fishery (or they never enter it) if they are less efficient. Competition between the two sectors implies that the fishery should be managed jointly in a sustainable manner.

This paper provides the idea for the creation of a protected area for recreational fisheries, which helps to redistribute recreational and commercial fishing activities onto different locations. However, aligning the management systems used for different sectors can be challenging due to the differing objectives and mechanisms. In addition, particular management policy will affect participants’ behavior differently and, in turn, will affect the aggregate stock and harvest differently. In this paper, we applied a typical analysis under different management regimes. This analysis consisted of a comparison between the harvest and stock biomass levels before and after the creation of the protected area for recreational fisheries, especially under open access conditions. 
The comparison showed that the establishment of the protected area for recreational fisheries can ensure that both sectors can participate in the fisheries and resolve the conflicts amongst participants, from the two sectors. Protected areas enhance both the aggregate harvests and the aggregate stock biomass, even when both sectors still operate under open access conditions. The application of optimal management regimes for recreational fisheries can help to increase the aggregate stock. The aggregate harvests, under optimal management regimes, may be either higher than, or smaller than those under protected areas, for open access recreational fisheries, depending on the magnitude of $S_{R_{m}}^{\infty}$ and $S_{R_{m}}^{*}$ compared to $\frac{m}{2}$.

The protected area for recreational fishing can help the fishery manager achieve optimal and sustainable use of the marine resource. This involves making equal use of the resource, considering the commercial fisheries always operate under open access conditions. However, a natural problem that arises from this situation is that the establishment of a protected area for recreational fisheries can lead to increased opposition from commercial fishermen. This opposition occurs because commercial fishermen are more efficient, and do not like losing their important fishing grounds; how managers deal with this problem is an important factor to consider. At this point we will consider Smith and Pollard (1996) , p.262 view of management:

"Fisheries management should aim to achieve optimal and ecologically sustainable utilisation of the living aquatic resources.” And they clarified concerns of fisheries management: 
"This involves making the best possible use of the aquatic environment, considering all of the values and uses to which it can be put, from fishing of all kinds (commercial, recreational and traditional) to non-capture uses such as those of conservation, tourism and development.”

From previous analysis, we know that managers can impose a fee on recreational fisheries in order to obtain optimal stock level. From a regulatory perspective, they could transfer this fee to commercial fishermen as compensation for their loss of fishing ground. In addition, the dispersal of stock biomass from a protected area to an outer area is also evidence of a benefit to commercial fishermen, which could convince them to support the creation of a protected area for recreational fisheries.

Conflicts between commercial and recreational fisheries increase globally and create challenges for fisheries' managers (Aas, 2007). This is primarily because each sector fails to recognize the impacts of their own activity on the other sectors and because recreational and commercial fisheries have been traditionally managed in isolation from each other. From our research, it is clear that only when we have a better understanding of recreational fisheries and their relationship with commercial fisheries, can we formulate more effective management plans to conserve and sustain the fish resources.

\section{Acknowledgement}

The authors are very grateful to Norwegian Agency for International Development Cooperation (NORAD), Project SRV2701 for financial funding. Ola Flaaten also 
acknowledges financial support from the Norwegian Research Council, Project no. 185150, Economic Effects of Marine Fishing Tourism - The Case of Coastal Regions in Norway.

\section{References}

Aas, Ø.,(Ed), 2007. Global Challenges in recreational Fisheries. Wiley-Blackwell, Oxford, UK.

Bishop, R.C.,Samples, K.C., 1980. Sport and Comercial Fishing Conflicts: A Theoretical Analysis. Journal of Environmental Economics and Management 7: 220-233.

Bohnsack, J.A., 1993. Marine Reserves: They Enhance Fisheries, Reduce Conflicts and Protect Resources. Oceanus (Fall): 67-73.

Clark, C.W., 2005. Mathematical Bioeconomics: Optimal Management of Renewable Resource. Wiley - Interscience, New Jersey, US

Clark, C.W.,Munro, G.R., 1975. The Economics of Fishing and Modern Capital Theory: A Simplified Approach. Journal of Environmental Economics and Management 2(92-106).

Coleman, F.C., Figueira, W.F., Ueland, J.S.,Crowder, L.B., 2004. The Impact of United States Recreational Fisheries on Marine Fish Populations. Science 305(5692): 1958-1960.

Connell, K.E.M.,Sutinen, J.G., 1979. Bioeconomic Model of Marine Recreational Fishing Journal of Environmental Economics and Management 6: 127-139. 
Flaaten, O.,Mjolhus, E. (2006). Nature Reserves as a Bioeconomic Management Tool: A Simplified Modeling Approach. Working Paper Series in Economics and Management No. 04/06, February 2006, Norwegian College of Fishery Science, University of Tromso, Norway.

Griffiths, M.H.,Lamberth, S.J.,2002. Evaluating the Marine Recreational Fishery in South Africa. In: Recreational Fisheries: Ecological, Economics and Social Evaluation (eds Pitcher, T.J. and Hollingworth, C.E.), Chapter 16, pp. 227-251. Blackwell Science, Oxford, UK.

Kar, T.K.,Matsuda, H., 2008. A Bioeconomic Model of a Single-Species Fishery with a Marine Reserve. Journal of Environmental Management 86(1): 171-180.

Laukkanen, M., 2001. A Bioeconomic analysis of the Northern Baltic Salmon Fishery: Coexistence versus Exclusion of Competing Sequential Fisheries Environmental and Resource Economics 18: 293-315.

McPhee, D.P., Leadbitter, D.,Skilleter, G.A., 2002. Swallowing the bait: Is Recreational Fishing Ecologically Sustainable. Pacific Conservation Biology 8: $40-51$.

Pezzey, J.C.V., Roberts, C.M.,Urdal, B.T., 2000. A Simple Bioeconomic Model of A Marine Reserve. Ecological Economics 33: 77-91.

Pitcher, T.J.,Hollingworth, C.E.,2002. Fish for Fun: Where's the Catch? In: Recreational Fisheries: Ecological, Economic and Social Evaluation In: (eds Pitcher, T.J. and Hollingworth, C.E.), Chapter 1, pp. 1-16. Blackwell Science, Oxford, UK. 
Post, J.R., Sullivan, M., Cox, S., Lester, N.P., Walters, C.J., Parkinson, E.A., Paul, A.J., Jackson, L.,Shuter, B.J., 2002. Canada's Recreational Fisheries: The Invisible Collapse? Fisheries 27(1): 6-17.

Rayns, N., MacDonald, T.,Read, A. (2006). Protected Commercial Fishing Areas (PCFAs) - A Concept for Improving Equity in Resource Allocation between Aquatic Resource Users. Sharing The Fish Conference 2006. http://www.fish.wa.gov.au/docs/events/ShareFish/papers/pdf/papers/TraceyMa cDonald.pdf. Australia.

Sanchirico, J.N.,Wilen, J.E., 2001. A Bioeconomic Model of Marine Reserve Creation. Journal of Environmental Economics and Management 42: 257-276. Smith, A.K.,Pollard, D.A., 1996. The Best Available Information - Some Case Studies from NSW, Australia, of Conservation-Related Management Responses Which Impact on Recreational Fishers. Marine Policy 20(3): 261-267.

Sumaila, U.R.,2002. Recreational and Recreational Fishers in Namibian silver kob fishery In: Recreational Fisheries: Ecological, Economic and Social Evaluation (eds Pitcher, T.J. and Hollingworth, C.E.), Chapter 4, pp. 53-62. Blackwell Science, Oxford, UK.

Toivonen, A.-L.,2002. A Survey of The Economic Value of Nordic Recreational Fisheries. In: Recreational Fisheries: Ecological, Economics and Social Evaluation (eds Pitcher, T.J. and Hollingworth, C.E.), Chapter 11, pp. 137-143. Blackwell Science, Oxford, UK. 